\title{
THE EFFECT OF CORTISONE ON THE URINARY EXCRETION OF 17-KETOSTEROIDS IN PATIENTS WITH CUSHING'S SYNDROME ${ }^{1}$
}

\author{
BY JOSEPH W. JAILER, JEAN LOUCHART, JAY J. GOLD,2 AND \\ A. I. KNOWLTON
} (From the Departments of Medicine and Obstetrics and Gynecology, College of Physicians and
Surgeons, Columbia University and the Presbyterian Hospital, New York, N. Y.)

(Submitted for publication December 2, 1952; accepted January 28, 1953)

\section{INTRODUCTION}

The administration of cortisone to patients with virilism associated with adrenal hyperplasia results in a marked decrease in urinary 17 -ketosteroid excretion (1-3) whereas no significant fall occurs in those patients whose virilism is due to an adrenal tumor $(4,5)$. The administration of cortisone inhibits pituitary adrenocorticotropin secretion causing secondary atrophy of the adrenals $(6,7)$; hence a decrease in 17 -ketosteroid excretion ensues in those patients in whom the normal pituitary-adrenal interrelationship is preserved.

The data obtained in patients with adrenogenital syndrome (4) as a result of the injection of cortisone stimulated a similar investigation of patients suffering from an allied disease, Cushing's syndrome. It is generally agreed that the manifestations of Cushing's syndrome are due to excessive 11-oxygenated corticosteroid secretion by the adrenal cortex, although the pituitary (8) and the hypothalamus (9) as well as the adrenal (10) have been postulated as the site primarily involved.

If either an adrenal or pituitary tumor is present, it seems reasonable that the source of excessive secretion responsible for the disease picture lies in the neoplastic tissue and in such patients because of the autonomous nature of the tumor no fall in 17-ketosteroids would be anticipated following the injection of exogenous cortisone. On the other hand if no tumor exists, the bilateral adrenal hyperplasia may arise de novo and be independent of pituitary control, or the normal pituitary-adrenal interrelationships may still be operating. If the latter obtains, then the administration

1 Aided by grants from the American Cancer Society as recommended by the Committee on Growth, National Research Council and the United States Public Health Service.

2 Fellow, American Cancer Society. of cortisone should result in a fall in the 17ketosteroid excretion.

Since the levels of urinary 17 -ketosteroid excretion in Cushing's syndrome are considerably lower than those encountered in the adrenogenital syndrome the results following the administration of cortisone would of necessity be less striking. However, if significant decreases in 17-ketosteroid excretion could be demonstrated, the administration of cortisone might provide a physiological method for determining whether the hyperplastic glands found in Cushing's syndrome are under pituitary influence. The present report describes the responses in urinary 17 -ketosteroid excretion of 6 patients with Cushing's syndrome during four to five days' administration of large doses of cortisone. $^{3}$

\section{METHODS AND MATERIALS}

A brief summary of the case histories of the 6 patients follows :

Patient 1. C. C. was a 29 year old woman with hypertension $(160 / 100)$, amenorrhea, decreased glucose tolerance, demineralization of the spine, buffalo obesity, striae, acne and paranoid reactions. In April 1951, the pituitary was irradiated with a total tumor dose of $3350 \mathrm{R}$ with only temporary improvement. In March of 1952, the present studies were conducted and subsequently a subtotal bilateral adrenalectomy was performed and the diagnosis of bilateral adrenal hyperplasia confirmed. Postoperatively the patient improved.

Patient 2. S. K. was a 20 year old male exhibiting all the manifestations of Cushing's syndrome-characteristic obesity, blood pressure of $206 / 140$, decreased glucose tolerance, multiple purple striae. A right partial adrenalectomy was performed in July 1951, with removal of $6.5 \mathrm{gms}$. of hyperplastic gland. Subsequently, pituitary irradiation in September 1951, totalling $4500 \mathrm{R}$ tumor dose, resulted in a temporary partial remission. The first cortisone study (2a) here reported was undertaken in April 1952.

\footnotetext{
3 The cortisone used in this study was kindly supplied by Dr. Elmer Alpert of Merck, Inc.
} 
Since the results of the cortisone test were not decisive it was repeated in October 1952 (2b). On November 7 1952 the right adrenal gland was removed in toto.

Patient 3. J. J. was a 29 year old policeman with documented Cushing's syndrome-facial obesity, blood pressure of 190/139, frank diabetes, severe acne, purple striae, compression fracture of the ninth thoracic vertebra and confused mental state. The cortisone study was performed April 1952. Subsequently, in the course of three operations, the greater portion of adrenals has been removed and no evidence of a tumor has been demonstrated. Postoperatively no adrenal substitution therapy was needed. One month after the third operation, pituitary irradiation (totalling $4000 \mathrm{R}$ tumor dose) was given and at present, two months after completion of X-ray therapy, the patient is not improved.

Patient 4. A. G. was a 30 year old housewife with Cushing's syndrome exhibiting rounding of the face, mild hypertension (140/90), amenorrhea, diabetic glucose tolerance curve. Subsequent to the present study with cortisone, a unilateral adrenalectomy in August 1952 established the diagnosis of adrenal hyperplasia.

Patient 5. H. H. was a 38 year old housewife with Cushing's syndrome manifested by moon-facies, buffalo hump, easy bruisability, mild hypertension (150/90) and 2 diabetic glucose tolerance curve. She had no roentgenological evidence of osteoporosis and her menses were normal. A left unilateral adrenolectomy was performed on January 14, 1953 and a hyperplastic adrenal weighing $12 \mathrm{gms}$. was removed.

Patient 6. C. R. was a 26 year old salesman whose Cushing's syndrome ran a fulminating course. His findings included rounding of the face, blood pressure of $190 / 120$, diabetes, purple striae, acne, confused mental state with toxic psychosis. A left adrenal carcinoma was removed at operation in December 1951. Two months later, metastases were discovered in the lungs and spine. The cortisone study here reported was undertaken in February 1952. Due to the rapid mental and physical deterioration of the patient, an hypophysectomy was performed by Dr. Lawrence Pool of the Neurological Institute. The patient subsequently died of carcinoma and sections of the contents of the sella turcica revealed no pituitary tissue.

\section{RESULTS}

Adrenal hyperplasia. The 5 patients with proven adrenal hyperplasia were each injected with $200 \mathrm{mg}$. of cortisone intramuscularly daily for four or more days (Table I). In all 5 patients, there was a significant decline in the excretion of urinary 17-ketosteroids. In 1 patient, S. K., the decline in 17-ketosteroids as a result of cortisone therapy was only 25 per cent (2a). However, when the experiment was repeated six months later an impressive reduction in 17-ketosteroid excretion (2b) was noted. There were no deleteri-
TABLE I

The effect of cortisone on urinary 17-ketosteroid excretion in patients with Cushing's syndrome

\begin{tabular}{|c|c|c|c|c|c|c|c|c|}
\hline \multirow{2}{*}{ Patient No. } & \multirow{2}{*}{1} & \multicolumn{2}{|c|}{2} & \multirow{2}{*}{3} & \multirow{2}{*}{4} & \multirow{2}{*}{5} & \multirow{2}{*}{6} & \multirow{2}{*}{7} \\
\hline & & $a$ & b & & & & & \\
\hline $\begin{array}{c}\text { Day } \\
\text { before cortisone } \\
4 \\
3 \\
2 \\
1\end{array}$ & $\begin{array}{r}14.3 \\
9.0\end{array}$ & $\begin{array}{l}22.1 \\
16.6\end{array}$ & \begin{tabular}{|l}
16.6 \\
13.8 \\
14.2 \\
12.9
\end{tabular} & $\begin{array}{l}29.9 \\
25.9\end{array}$ & $\begin{array}{l}23.8 \\
22.9\end{array}$ & $\begin{array}{l}19.2 \\
20.2\end{array}$ & $\begin{array}{l}51.6 \\
40.8 \\
39.3\end{array}$ & $\begin{array}{l}21.2 \\
17.0\end{array}$ \\
\hline $\begin{array}{l}\text { on cortisone } \\
100-200 \mathrm{mg} / \mathrm{dag}\end{array}$ & & & & & & & & \\
\hline $\begin{array}{l}1 \\
2 \\
3 \\
4 \\
5\end{array}$ & $\begin{array}{l}6.3 \\
5.8 \\
3.6\end{array}$ & $\begin{array}{l}13.8 \\
14.2 \\
12.6 \\
13.1\end{array}$ & $\begin{array}{r}12.9 \\
14.0 \\
5.8 \\
6.3\end{array}$ & $\begin{array}{l}22.9 \\
23.6 \\
19.2\end{array}$ & $\begin{array}{r}11.2 \\
8.0 \\
11.0 \\
13.5\end{array}$ & $\begin{array}{l}11.4 \\
14.8 \\
12.4 \\
11.3\end{array}$ & $\begin{array}{l}53.1 \\
56.1 \\
63.0 \\
59.3\end{array}$ & $\begin{array}{l}12.2 \\
13.4\end{array}$ \\
\hline
\end{tabular}

Patients 1 to 5: adrenal hyperplasia

Patient 6: adrenal carcinoma

Subject 7: normal male

ous effects of the administered cortisone on any of the patients.

Adrenal carcinoma. It has been reported that Cushing's syndrome due to adrenal carcinoma may be accompanied by a wide variation in the levels of 17-ketosteroid excretion, but that the amounts of these substances are usually elevated (11). In the patient here reported the control values were definitely, though not extraordinarily, elevated. The administration of $100 \mathrm{mg}$. a day of cortisone for four days intramuscularly was without demonstrable effect upon the 17-ketosteroid output (Table I, No. 5). Apparently the tumor in this patient was autonomous and, unlike normal or hyperplastic adrenal tissue, was not under pituitary control. Hence pituitary inhibition as achieved by cortisone administration was without effect upon the secretion of 17 -ketosteroid precursors. This was further borne out by the fact that following the complete hypophysectomy the level of urinary 17-ketosteroids and the clinical course remained unchanged.

Normal individuals. It has been amply demonstrated that when therapeutic doses of cortisone are administered to normal individuals there is a fall in 17-ketosteroid excretion. Thus, as can be seen from the table (No. 7), the administration of $200 \mathrm{mg}$. per day of cortisone in a normal male resulted in a 40 per cent decline in total neutral 17-ketosteroids. 


\section{DISCUSSION}

It is not clear whether the physiological manifestations of Cushing's syndrome result from excessive amounts of adrenocorticotropin stimulating the adrenal glands or whether the overproduction of corticosteroids arises spontaneously within the adrenals. There are several indications from available clinical material which suggest that the first of these possibilities is the more commonly encountered abnormality: 1) Adenomas of the pituitary occur in 50 per cent of the cases while adrenal tumors, including benign and malignant types, are found in less than 30 per cent of such patients $(12), 2$ ) irradiation of the pituitary results in some degree of improvement in at least 30 per cent, and 3) both adrenal cortices show hyperplasia in a high per cent of the cases ( 58 per cent) (12). As mentioned above, there is ample evidence that one of the physiological actions of cortisone or of compound $F$ is to suppress ACTH secretion by the adenohypophysis $(6,7,13)$. This has been demonstrated in the virilizing syndrome $(1-4)$. The fall in urinary $17-$ ketosteroids which occurs in Cushing's syndrome as a result of cortisone administration is in all probability similarly mediated. The present findings provide evidence for the speculation that the hyperplastic adrenal glands in Cushing's syndrome remain under pituitary control since, when ACTH secretion is suppressed by cortisone, the concomitant fall in urinary 17-ketosteroid secretion reflects a decreased cortical activity. Such a fall did not occur in the one patient with an adrenal carcinoma. The presumed suppression of his pituitary ACTH secretion by cortisone was without effect since the great bulk of the precursors of the 17-ketosteroids was provided by the autonomous tumor which was free of pituitary control. This was subsequently confirmed when complete hypophysectomy failed to alter the 17 -ketosteroid values.

These results bring up another point of speculation. If suppression of adrenocortical activity occurs as a result of exogenous cortisone or compound $F$ administration (4) and there is a resultant decline in urinary 17 -ketosteroids, the adrenal must be secreting other steroids which are 17-ketosteroid precursors besides cortisone and compound F. The latter are known to be degraded and excreted as 17-ketosteroids to a cer- tain extent $(14,15)$. It is possible that the adrenal contribution to the 17 -ketosteroids includes an androgen. Assay of cow adrenal vein blood has demonstrated the existence of an adrenal androgen (16).

\section{SUMMARY}

The urinary excretion of 17-ketosteroids in 6 patients with Cushing's syndrome has been studied during a four to five day period of exogenous cortisone administration.

No alteration was observed in the abnormally high excretion of 17 -ketosteroids in 1 patient with a metastatic adrenal tumor.

Significant decreases in 17-ketosteroid levels were noted in 5 patients with proven hyperplastic adrenal cortices.

\section{REFERENCES}

1. Wilkins, L., Lewis, R. A., Klein, R., Gardner, L. I., Crigler, J. F., Jr., Rosemberg, E., and Migeon, C. J., Treatment of congenital adrenal hyperplasia with cortisone. J. Clin. Endocrinol., 1951, 11, 1.

2. Bartter, F. C., Albright, F., Forbes, A. P., Leaf, A., Dempsey, E., and Carroll, E., The effects of adrenocorticotropic hormone and cortisone in the adrenogenital syndrome associated with congenital adrenal hyperplasia: An attempt to explain and correct its disordered hormonal pattern. J. Clin. Invest., 1951, 30, 237.

3. Jailer, J. W., Recent studies on adrenal hyperplasia. Tr. N. Y. Acad. Sc., 1951, 13, 262.

4. Jailer, J. W., Louchart, J., and Cahill, G. F., Adrenal virilism. I. Diagnostic considerations and treatment. J. A. M. A., 1952, 150, 575.

5. Gardner, L. I., and Migeon, Cl. J., Le diagnostic des tumeurs virilisantes du cortex surrénalien: effet de la cortisone sur les stéroides urinaires et utilisation d'une méthode colorimétrique pour le dosage de la dehydroisoandrostérone. Helvet. paediat. acta, 1951, 6, 465.

6. Sayers, G., The adrenal cortex and homeostasis. Physiol. Rev., 1950, 30, 241.

7. Ingle, D. J., The biologic properties of cortisone: a review. J. Clin. Endocrinol., 1950, 10, 1312.

8. Cushing, $H$., The basophil adenomas of the pituitary body and their clinical manifestations (pituitary basophilism). Bull. Johns Hopkins Hosp., 1932, 50, 137.

9. Heinbecker, P., The pathogenesis of Cushing's syndrome. Medicine, 1944, 23, 225.

10. Kepler, E. J., Sprague, R. G., Mason, H. L., and Power, M. H., The pathologic physiology of adrenal cortical tumors and Cushing's syndrome. Recent Progress in Hormone Research, 1948, 2, 345. 
11. Forbes, A. P., and Albright, F., A comparison of the 17-ketosteroid excretion in Cushing's syndrome associated with adrenal tumor and with adrenal hyperplasia. J. Clin. Endocrinol., 1951, 11, 926.

12. Plotz, C. M., Knowlton, A. I., and Ragan, C., The natural history of Cushing's syndrome. Am. J. Med., 1952, 13, 597.

13. Perera, G. A., Fleming, T. C., Pines, K. L., and Crymble, M., Cortisone in hypertensive vascular disease. J. Clin. Invest., 1950, 29, 739.

14. Thorn, G. W., Forsham, P. H., Bennett, L. L., Roche, M., Reiss, R. S., Slessor, A., Flink, E. B., and Somerville, W., Clinical and metabolic changes in Addison's disease following the administration of compound $\mathrm{E}$ acetate (11-dehydro, 17-hydroxycorticosterone acetate). Tr. A. Am. Physicians, 1949, 62, 233.

15. Sprague, R. G., Power, M. H., Mason, H. L., Albert, A., Mathieson, D. R., Hench, P. S., Kendall, E. C., Slocumb, C. H., and Polley, H. F., Observations on the physiologic effects of cortisone and ACTH in man. Arch. Int. Med., 1950, 85, 199.

16. Gassner, F. X., Nelson, D. H., Reich, H., Rapala, R. T., and Samuels, L. T., Isolation of an androgenic compound from the adrenal venous blood of cows. Proc. Soc. Exper. Biol. \& Med., 1951, 77, 829. 